\title{
Homenaje a Juan Noemi Callejas
}

\author{
Fredy Parra Carrasco
}

El día 30 de abril se realizó en el Centro de Extensión de nuestra Universidad un homenaje al Profesor Doctor don Juan Noemi Callejas. A la presentación de la trayectoria teológica del Profesor Noemi por parte del decano Fredy Parra, siguieron las intervenciones de los profesores Eduardo Silva y Mariano de la Maza de las Facultades de Teología y Filosofía respectivamente.

Juan Noemi nace el 20 de enero de 1942 en Freirina (Chile). Hijo de Alejandro Noemi Huerta y Olga Callejas Zamora. Entre 1962 y 1966, en plena celebración del Concilio Vaticano II, estudia en la Universidad Gregoriana de Roma y en julio de 1966 obtiene el grado de Licenciado en Teología. Asiste a las clases de teólogos y especialistas como Antonio Orbe, Bernard Lonergan e Ignace de la Potterie, entre otros. Después continúa sus estudios de Doctorado en Alemania en etapas consecutivas desde 1967 a 1969 y desde 1973 a 1975, en la Facultad de Teología Católica de la Universidad de Münster. Entonces enseñaban en allí teólogos como Walter Kasper, Juan Bautista Metz, Karl Rahner, Joseph Ratzinger. En enero de 1976 obtiene el grado de "Doktor der Theologie" conferido por la Universidad de Münster.

En mayo de 1968 inicia su carrera académica en la Facultad de Teología de la Pontificia Universidad Católica de Chile como docente de Teología Dogmática. En 1976 es promovido al grado de profesor adjunto y en $1983 \mathrm{al}$ de titular. Se convierte así en el primer laico que ha ocupado una cátedra como profesor titular en la Facultad de Teología de la Universidad Católica de Chile. En la misma Facultad ha desempeñado los cargos de miembro del Consejo Académico en varios períodos, $\mathrm{Di}$ rector del programa del Postgrado (Magíster y Doctorado), Director de la Revista Teología y Vida, Vicedecano y finalmente Decano 
entre los años 2001 y 2004, fue el primer laico en llegar a este cargo en la historia de nuestra Facultad. Ejerció también la docencia fuera de nuestra patria, como profesor invitado de la Facultad de Teología de Cataluña (Barcelona) entre 1990 y 1991.

A lo largo de 40 años ha sido un destacado docente e investigador de nuestra Facultad. Ha dedicado gran parte de su tiempo a la dirección de tesis, especialmente doctorales, colaborando directamente, en la formación de nuevos teólogos para el servicio intelectual en la Iglesia chilena. El legado académico, la herencia de Juan Noemi Callejas, entre sus alumnos y colegas, consiste sobre todo en su aguda criticidad y finura para despertar el interés y la pasión por el conocimiento teológico. Se recuerda y valora igualmente su exigencia de rigor en el pensar y en el estudio teológico y su insistencia en la necesaria mediación de la filosofía en el quehacer teológico, dado que el creer no solo presupone el ejercicio de la razón, sino que esta, a su vez, permite el desarrollo de las posibilidades y potencialidades de la misma fe.

Diversos teólogos y teólogas, varios de ellos ex alumnos de Juan Noemi le manifestamos nuestro agradecimiento y reconocimiento con la publicación de un volumen de Anales de la Facultad de Teología que hemos titulado "La inteligencia de la esperanza", y lo hacemos como un homenaje al amigo y maestro. Junto con este número de Anales se presenta la más reciente obra de Juan titulada Credibilidad del cristianismo. La fe en el horizonte de la modernidad, recientemente publicada.

No puedo dejar de destacar un aspecto central del legado de Juan y que explica el título del número de Anales al que me he referido: Inteligencia de la esperanza. En medio de las complejas y difíciles circunstancias históricas vividas por nuestro país y por nuestro continente, Juan nos ha enseñado a esperar y a fundamentar nuestra esperanza.

Nos ha hecho ver y valorar el llamado del Concilio Vaticano II a dialogar críticamente con la racionalidad moderna, especialmente con su afirmación de la historicidad y libertad humana, en el horizonte de la esperanza escatológica.

Más allá de todo dualismo entre presente y futuro, este teólogo propone buscar y fundamentar una relación fecunda entre el presente histórico y el futuro. Y en esa búsqueda hace ver que una perspectiva sintética encuentra su fundamento tanto en la articulación 
que el yahvismo hace del futuro como en la que se establece en los evangelios con el anuncio del reinado de Dios. Nos propone una visión integradora del presente y del futuro. En su planteo no cabe una visión dicotómica entre inmanencia y trascendencia. Lo viable es pensar que la esperanza escatológica de la tradición bíblica valora un presente abierto al futuro de la plenitud. Y si el presente está abierto hacia una consumación se encuentra en camino hacia un futuro nuevo y, en consecuencia, es modificable, transformable. Esta experiencia de la esperanza hace posible la responsabilidad histórica, esto es, una acción transforma- dora con su ineludible dimensión política.

Juan nos ha enseñado que lo escatológico constituye un saber sobre lo definitivo de Dios, sobre lo último, que acaba afectando positivamente a la eclesiología, a la teología del mundo y a la antropología, a la visión de la historia y de los signos de los tiempos. Con este enfoque, toda la teología queda penetrada por la perspectiva escatológica, esto es, atravesada por una tensión temporal positiva, donde sus contenidos permanecen dependientes y relativos al éschaton, remitidos a una plenitud -la consumación escatológica- todavía pendiente. 
